\title{
The Role of Occupational Characteristics and Occupational Imbalance in Explaining Well-being
}

\author{
Dana Anaby • Tal Jarus • Catherine L. Backman • \\ Bruno D. Zumbo
}

Received: 10 July 2009 / Accepted: 9 February 2010 / Published online: 13 March 2010

(C) Springer Science+Business Media B.V./

The International Society for Quality-of-Life Studies (ISQOLS) 2010

\begin{abstract}
One of the key factors for promoting well-being lies in balancing one's daily life occupations and the nature of these occupations. Occupation refers to a group of everyday life goal-directed activities which may be associated to any life domain, not necessarily work, such as leisure, education, or self-care. Yet it is not clear what constitutes occupational imbalance, and its association to other factors has not been examined systematically. This study proposed and tested a theoretical model for specifying the structural relationships between occupational imbalance, occupational characteristics, personality and well-being. 288 working adults completed the following questionnaires: Inter-goal Relations Questionnaire (occupational imbalance), Personal Projects Analysis (occupational characteristics), the Big Five Inventory (personality traits) and the Satisfaction with Life Scale (well-being). Twenty-five models were tested using structural equation modeling. All the models fit the data well. Occupational characteristics, with the exception of stress, served as significant mediators between personality and well-being, yet occupational imbalance did not play a significant role across all models. Our findings provide substantial support for the importance of
\end{abstract}

D. Anaby $(\bowtie)$

School of Rehabilitation Science, McMaster University, 1400 Main Street West, Hamilton, ON L8S 1C7, Canada

e-mail: anabydan@gmail.com

T. Jarus $\cdot$ C. L. Backman

Department of Occupational Science and Occupational Therapy, CanDo research center, University of British Columbia, T325-2211 Wesbrook Mall, Vancouver, BC V6T 2B5, Canada

T. Jarus

e-mail: tal.jarus@ubc.ca

C. L. Backman

e-mail: catherine.backman@ubc.ca

B. D. Zumbo

Measurment, Evaluation and Research Methodology, University of British Columbia,

Building 2125 Main Mall, Vancouver, BC V6T 1Z4, Canada

e-mail: bruno.zumbo@ubc.ca 
occupation to well-being, however occupational imbalance is still an elusive concept that requires further investigation theoretically and empirically.

Keywords Well-being $\cdot$ Life balance $\cdot$ Personality $\cdot$ Occupation

\section{Introduction}

Subjective Well-Being (SWB) refers to the way individuals perceive their life as a whole (Diener 1984). This concept of SWB is gaining attention as an important outcome measure to assess for treatment efficacy in rehabilitation clinical studies (AOTA 2002; WHO 2001). In the area of psychology, in particular personality research, it has been suggested that a key factor for explaining SWB lies in the nature of one's everyday life activities (or goal-directed pursuits) and finding balance among these activities (Little 1983; Little and Chambers 2004). Personality has been recognized as another important factor that affects not only well-being (Diener et al. 1999) but also influences the way people choose, structure and perceive their daily activities (Furnham 1981; Little et al. 1992). The notion of daily activities and their effect on well-being is studied in other fields such as occupational therapy and occupational science (Yerxa et al. 1989). Although the terminology across fields is different it represents similar concepts. In occupational therapy and occupational science, occupation is defined in a broader way than typically viewed. It refers to a group of everyday life goal-directed activities, has meaning for the individual, and is familiar to their culture (CAOT 1997). Thus, occupations are attributed to any life domain, not necessarily just work, such as leisure, education, self care and more. Similarly, the concept of balance in occupations is closely related to other terms such as work-life balance, yet it is distinct. Therefore, occupational balance addresses all life domains not necessarily just work and looks at the way individuals find balance among different kinds of activities (e.g., learning, playing, socializing etc.). Yet there is a lack of evidence on what constitutes a balanced state among occupations, how it is associated with the characteristics of those occupations and one's personality traits, and in turn how it is associated with well-being.

It is important to develop integrated theoretical models to better understand the role of occupation and occupational balance in explaining well-being; at the same time, these models need to be empirically tested in order to provide a substantial contribution. Furthermore, developing theoretical models which are interdisciplinary in nature might improve our understanding of human behavior, reflected in occupations, and its effect on well-being. Such models might guide various fields of practice that consider the doing aspect of their clients as a vehicle for promoting well-being (e.g., occupational therapists, psychologists, recreational therapists, vocational counselors among others). Thus, the purpose of this study is to propose a theoretical model based on knowledge from the research fields of personality, occupational therapy and occupational science, and to test it empirically using structure equation modeling (SEM).

The literature was reviewed in order to articulate a conceptual model for empirical testing. Occupational balance, well-being, and related factors are defined based upon the theory from which they were derived, and the review suggests how these 
concepts are related to each other. Subsequently, a proposed theoretical model is outlined to illustrate the study's hypothesis, presented in Fig. 1.

\section{Occupation-A Potential Construct in Explaining Well-being}

Theoretical approaches in the area of psychology (Csikszentmihalyi and Hunter 2003; Little 1984) and occupational therapy (Meyer 1977; Reilly 1966; Yerxa et al. 1989) recognize the potential of daily life activities (or goal-directed pursuits) in expressing individual differences and explaining well-being. People's specific behavioral tendencies, which are reflected in daily life activities, have been termed by Little (1996) as Personal Action Construct (PAC) units. Examples of such units are: personal projects (Palys and Little 1983); personal goals (Riediger 2007) and occupations (Law et al. 1996). These PAC units can include, for example, writing an article with Dr. Fox, making an album for my sister's 50th birthday, or getting a promotion to assistant manager. In personality research, the term personal project is used to refer to interrelated sequences of actions intended to achieve some personal goal (Little 1983) and naturally share common elements with the term personal goal (Little 2007). In occupational therapy theory, the term occupation is defined more broadly than typically understood and refers to groups of everyday life activities which are goal-directed, have meaning for the individual, and are familiar to his or her culture (Law et al. 1996). Thus, the term occupation is not necessarily limited to employment-related activities, but refers to any activity people engage in to occupy themselves in any life domain.

The concept of personal project exhibits the four elements common to definitions of occupation suggested by Christiansen and Baum (2005) as they are: (a) goal-directed (b) contextual (c) culturally identifiable and (d) have meaning to the doer. Not only are these configurations of action units, (occupations, personal projects and personal goals) conceptually similar but they are also empirically comparable (Omodei and Wearing 1990; Riediger 2007). Thus, this paper will use occupation to represent both personal projects and personal goals, and the Personal Project Analysis as a method to study occupation.

Fig. 1 The hypothetical model

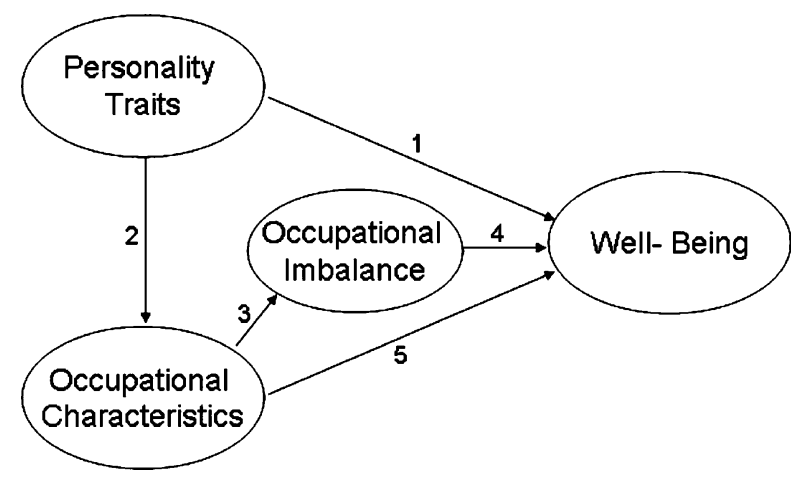




\section{Occupational Characteristics and Well-being (see Fig. 1, path 5)}

There is considerable theoretical support that occupation is a source of well-being and a mechanism for meeting intrinsic needs and interests (e.g., Christiansen and Baum 2005; Law et al. 1996; Wilcock 1998). Yet, knowledge about the specific characteristics of daily occupations that promote health and well-being is limited. Little (1984) developed a method for measuring people's reasons for pursuing projects or occupations labeled Personal Projects Analysis (PPA). This method frames the way individuals perceive their personal projects or occupations in terms of five characteristics: meaning, structure, community, efficacy and stress. Meaning refers to the way the individual perceives his or her occupations as rewarding, valuable and worthwhile. The second characteristic, structure, refers to the sense that one's occupations are organized and under control. Community refers to the perception that others view one's occupations as important, and efficacy relates to the perception that one will be successful in completing occupations. The last characteristic, stress, reflects aspects of difficulty, challenge and stress due to engagement in occupations. Little (1984) suggested that appraising occupations through these five characteristics explains an individual's SWB.

Several studies indicate a relationship between occupational characteristics and wellbeing. For example, occupations with meaning to the individual have a positive association with SWB (e.g., Clark et al. 1997; Palys and Little 1983). Additionally, McGregor and Little (1998) found that enjoyable, supported and efficient occupations were associated with a higher level of well-being, whereas Lecci et al. (1994) showed that persons scoring high on measures of depression rate their occupations as more stressful and difficult. Similarly, other studies have shown that participants whose occupations are characterized by a high level of efficacy, control, and meaning, and by low levels of stress reported a higher level of well-being (Christiansen et al. 1999; Christiansen 2000; McGregor and Little 1998; Yetim 1993). Studies found that occupations that are supported and valued by others (the community characteristic) have a positive effect on well-being (Salmela-Aro and Little 2007; Wallenius 1999; Wenzel 2000). Hence, there is considerable support, theoretically as well as empirically, for the relation between occupational characteristics and well-being.

\section{Occupational Balance and Well-being (see Fig. 1, path 4)}

The literature in occupational therapy, in the very early stages of the profession's development, purported theoretical support for the tenet of occupational balance, suggesting that a balance among one's occupations promoted well-being and health (McColl et al. 1993; Meyer 1977; Reilly 1966). In fact, this notion has become increasingly prevalent in recent literature (e.g., Backman 2004; Christiansen 1996; Christiansen and Matuska 2006; Håkansson et al. 2006; Jonsson and Persson 2006; Westhorp 2003; Wilcock et al. 1997), yet it is somewhat a contested concept with little consensus on how it is defined and best measured. This study views occupational balance from a socio-ecological perspective considering the personal and contextual influences under which people act. Occupational balance, according to this approach, focuses on the interaction among one's occupations where harmony 
or facilitation among them implies a state of balance, and conflict or interference among occupations suggests a lack of balance; both are based on personal perception (Christiansen 1996).

Studies exploring the relationship between occupational balance and well-being by looking at the impact among occupations (level of conflict/interference and harmony/facilitation) using a single scale (where interference and facilitation are measured as opposite poles of a single scale) have not yielded consistent results (Christiansen et al. 1999; Palys and Little 1983; Wallenius 2000). Recently it has been shown that interference and facilitation among occupations are distinct dimensions that co-exist. In fact, they are differently related to well-being: interference, or occupational imbalance, demonstrates a statistically significant association with SWB, but facilitation, or occupational balance, does not (Riediger and Freund 2004; Riediger et al. 2005; Riediger 2007). Therefore, this study will focus on the interference dimension of the concept which represents the level of imbalance among occupations.

\section{Occupational Characteristics, Occupational Imbalance and Well-being (see Fig. 1, paths 3, 4 and 5)}

One factor that might influence the relation between imbalance among occupations and well-being is related to the characteristics of these occupations. This influence is a result of the relation between occupational characteristics and occupational imbalance. For example, structured occupations (well-organized and in one's control, easier to manage) reduce one's sense of imbalance and therefore contribute to greater SWB. On the other hand, stressful occupations may lead to higher levels of imbalance as they are more complicated to manage, and therefore result in lower SWB. Indeed, the literature provides evidence for this relationship. In a study of people 18-64 years old, involvement in occupations characterized by a low level of enjoyment and a high level of difficulty were associated with conflict (occupational imbalance) and low levels of life satisfaction (Palys and Little 1983). Similarly, Håkansson et al. (2006) found that engaging in meaningful occupations with a sense of control enabled people to achieve balance in everyday life. Therefore, in addition to the direct effect of occupational characteristics on well-being, the occupational characteristics might have an effect on well-being through their effect on occupational imbalance.

\section{Personality and Well-being and the Relation to Occupation (see Fig. 1 paths 1, 2 and 5)}

One of the most consistent variables in its ability to explain SWB is personality traits (Diener et al. 1999). There are five main groups of personality traits that are generally accepted in the literature: extraversion, openness, neuroticism, agreeableness and conscientiousness (John and Srivastava 1999). Neuroticism is negatively associated with well-being, while openness, agreeableness, extraversion and conscientiousness are positively related (DeNeve and Cooper 1998). Studies show that well- 
being is mostly influenced by extraversion and neuroticism. Extraversion is related to positive affect and neuroticism is related to negative affect (Diener et al. 1999; Watson and Clark 1997).

Beyond the relationship between personality and well-being it seems that personality affects the way people choose and perceive their occupations. Little et al. (1992) suggest that the five characteristics of personal projects/occupations are related to the five personality traits. For example, it was found that neuroticism is related to the occupational characteristics of stress, structure and meaning, while extraversion and conscientiousness was positively correlated with meaning, efficacy and community (Little et al. 1992). This provides empirical support for the relationship between personality and occupational characteristics. At the theoretical level, the socio-ecological model of personality proposed by Little (1999) positions PAC units (e.g., occupations) as mediators between one's disposition and well-being. Thus, well-being is influenced by occupational characteristics, which in turn is influenced by one's personality traits. In other words, the relation between personality and well-being is mediated by one's occupational characteristics.

\section{The Present Study}

To summarize, this literature review identified two factors that mediate the effect of personality on well-being: occupational characteristics and occupational imbalance. It was found that occupational characteristics serve as mediators between personality and well-being. In addition, occupational imbalance serves as mediator between occupational characteristics and well-being. Hence, well-being is influenced by occupational imbalance, which is influenced by the characteristics of the occupations one engages in, which in turn is influenced by one's personality traits. The literature reviewed here provides the rationale for the hypothetical model presented in Fig. 1.

Figure 1 presents the structural relationship between personality, occupational characteristics, occupational imbalance and well-being. Our general hypothesis is that the proposed model will fit the data. Looking at Fig. 1 from left to right we specifically hypothesize that: 1) Personality traits, occupational characteristics and occupational imbalance have a direct effect on well-being (see paths 1, 4 and 5); 2) Occupational characteristics serve as mediator between personality and well-being and (see paths 2 and 5) 3); and Occupational imbalance serves as a mediator between occupational characteristics and well-being (see paths 3 and 4).

\section{Method}

Participants and Procedures

The present cross-sectional study included a convenience sample of 288 working adults, between the ages of 27-60 living in Israel. Participants needed to (a) have a minimum of 10 years of education, (b) be employed for at least $20 \mathrm{~h}$ a week and for a minimum of two years to ensure participants' jobs were not new (which might affect occupational imbalance and well-being), and (c) be without any physical or 
emotional disabilities. Shift workers were excluded from the study as their working style might affect their occupational imbalance. A snowball sampling method was used to recruit participants. Ten trained occupational therapy students advertised for the study in their own community and recruited participants that met the inclusion and exclusion criteria. Data were collected during an individual meeting that took place in a quiet setting chosen by the participants. After signing a consent form, participants completed self-administered questionnaires which were set in random order. All the measurements were translated to the Hebrew language via translation-back translation method. The study was approved by the Behavioural Research Ethics Board of Tel Aviv University.

\section{Measures}

\section{Subjective Well-being (SWB)}

This variable was operationally defined by the five-itemed Satisfaction with Life Scale (SWLS) (Diener et al. 1985). This questionnaire assessed the cognitive perspective of SWB where the individual was asked to judge their satisfaction with life as a whole. It contained five statements in which participants were asked to rate their level of agreement on a scale ranging from 1 (strongly disagree) to 7 (strongly agree). Thus, each indicator score ranges from 1 to 7 . A summed score was generated ranging from 5 (totally disagree/minimal life satisfaction) to 35 (totally agree/maximal life satisfaction).

The scale has demonstrated adequate internal consistency (mean Cronbach's alpha across studies was 0.78 (Vassar 2008) and a two-month stability coefficient of 0.82 (Pavot and Diener 1993). Factor structure of the scale supported its validity confirming a single-factor solution (Arrindell et al. 1991; Pavot and Diener 1993) and its construct validity was demonstrated with its association to other measures of well-being (Pavot and Diener 1993). These findings were replicated in examining the Hebrew version of the scale (Anaby et al. 2010). In the present study its single-factor structure was verified using Confirmatory Factor Analysis (see "Results" section) and Cronbach's alpha coefficient was 0.83 .

Occupational characteristics were measured using the Personal Projects Analysis (PPA) (Little 1984). This questionnaire examined the individual's perception of their own unique occupational system. Two of the PPA modules were used: the Eliciting Project Lists and the Rating Matrix. First, the individual was asked to list 10 current occupations, then rate those occupations on a matrix of 15 items using an 11-point scale for each item (e.g., to what extent is this occupation important to you? Use 0 if the occupation has no importance at all and 10 if it's very important). The 15 items clustered on 5 factors that represent the characteristics of occupation according to Little (1984): meaning (5 items: enjoyment, identity, value, importance and absorption), structure (3 items: time adequacy, control, initiation), community (2 items: visibility, others' view), efficacy (2 items: progress, outcome) and total stress ( 3 items: difficulty, challenge, stress). The mean of items comprised the score for each factor, ranging from 0 to 10 . The PPA has demonstrated adequate criterion and construct validity (Christiansen et al. 1999; Little et al. 1992; Palys and Little 1983); internal consistency (Cronbach's $\alpha=0.7$ ) and stability for up to 
two weeks (Backman 2001; Little et al. 1992). In the present study the Cronbach's alpha coefficient for meaning was 0.86 , structure 0.70 , community 0.80 , efficacy 0.65 and stress 0.64 .

Occupational imbalance was operationally defined by four indicators that represent levels of interference among occupations in terms of money, time, energy and incompatibility. These indicators were derived from the Interference scale of the Inter-goal Relations Questionnaire (IRQ) (Riediger and Freund 2004). Participants selected four occupations that they considered core occupations from those listed on the PPA. Level of interference was rated in terms of time, energy and financial constraints (i.e., How often can it happen that, because of the pursuit of occupation A, you do not invest as much time/energy/money into occupation B as you would like?); and in terms of incompatibility between occupations (i.e., How often can it happen that you do something in the pursuit of occupation $A$ that is incompatible with occupation B?). The participants were asked to compare each pair of occupations according to each of the four items using a 5-point scale ranging from 1 (never/very rarely) to 5 (very often). Means were calculated and scores ranged from 1 (minimum interference among occupations) to 5 (maximum interference among occupations). Each pair of occupations is being compared twice to examine: 1) how occupation A influences occupation B and 2) how occupation B influences occupation A. In the IRQ there were four occupations and four items thus there were 12 possible comparisons for each item and all together 48 comparisons $(12 \times 4)$. Therefore, each indicator represented the mean of its 12 items ranging from 1 to 5 . Construct validity of the interference scale was demonstrated among old and young adults indicating a one-factor solution as well as excellent internal consistency (Cronbach's $\alpha=.94$ ) (Riediger and Freund 2004). In this present study the Cronbach's alpha coefficient was 0.78 and a single-factor structure was confirmed (see "Result" section).

Personality traits were measured using the Big Five Inventory (BFI) (John and Srivastava 1999) that assessed five personality domains: neuroticism (8 items), extraversion ( 8 items), openness (10 items), agreeableness (9 items) and conscientiousness (9 items). Participants estimated their level of agreement with 44 items using a 5-point scale ( 1 =disagree strongly, 5=agree strongly). Mean scores were calculated for each personality domain and ranged between 1 to 5 . Internal consistency ( 0.83 on average) and stability as well as criterion validity against NEO-Five Factor Inventory and Trait Descriptive Adjectives were established (John and Srivastava 1999). In the present study, the coefficient alpha for each domain was: neuroticism 0.81 , extraversion 0.77, agreeableness 0.58 , openness 0.56 and conscientiousness 0.74 .

Demographic variables were collected using a demographic questionnaire where three indicators of socio-economic status (SES) were assessed: 1) income 2) education 3) household density. The last indicator addressed population density inside the housing unit in terms of person per room (Lawrence 2006). A ratio between number of people living in the household and number of rooms was calculated. Lower ratios indicated lower levels of density and higher levels of SES.

\section{Data Analysis}

Once the functional relations between the factors were formulated into a model, the model identification phase took place. This phase was to ensure that the model is 
over-identified, i.e., number of parameters known is greater than parameters estimated, so that parameter estimation is possible (Bollen and Long 1993). The latent variable of well-being was operationalized by five indicators derived from the SWLS items, and the latent variable of occupational imbalance accounted for four indicators derived from the IRQ. According to the literature occupational characteristics are five distinct domains (Little 1984) rather than one latent variable as well as personality traits (John and Srivastava 1999), and thus we could not set them in one model. Therefore, we have set separate models. In each model one personality trait was present together with one occupational characteristic where the well-being and imbalance factors were consistently present in all the models. Since there were five personality traits and five occupational characteristics we set 25 different models (Fig. 2).

Based on the theory and the measurements' instructions each personality trait and occupational characteristic was treated as an observed variable (indicator). This ensured our model was over-identified allowing for estimation of the model parameters and assessing fit. Hence, our models included both observed variables and latent variable. When latent variables were present in the same model with observed variables, EQS (a statistical software for model testing) required that all the variables would be presented as latent variables (Byrne 2006). To be able to address each occupational characteristic as well as each personality trait as a latent variable with only one indicator, we have calculated the error of each indicator based on the

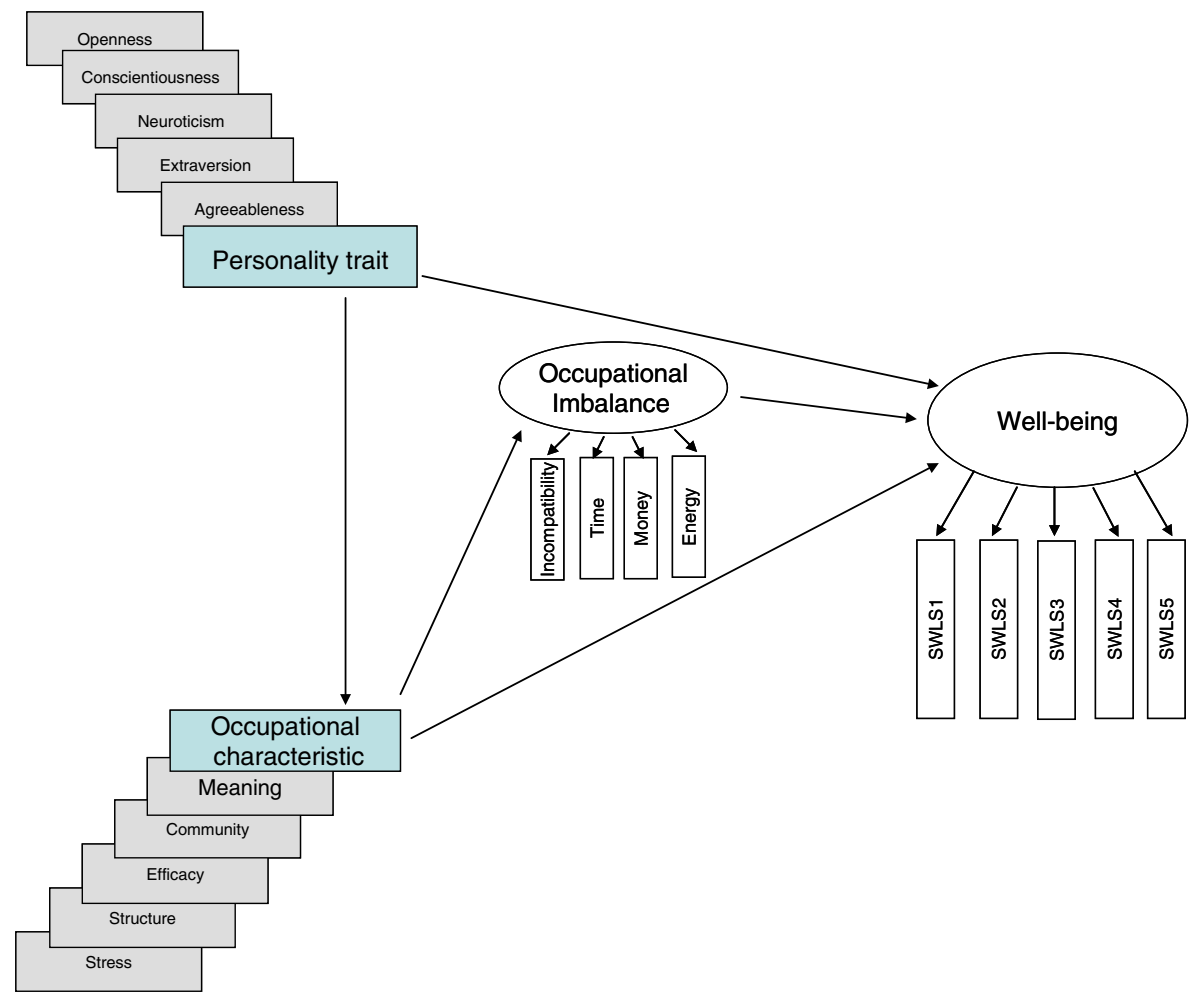

Fig. 2 The 25 variations of the proposed model 
following formula: error $=\operatorname{var}^{*}(1-\alpha)$ (Jöreskog and Sörbom 1993; McDonald and Seifert 1999). In summary, each model included 11 observed variables and 27 estimated parameters.

Finally, the estimation phase took place and incorporated two sub-phases: the measurement model and the structural model. Both sub-phases were tested via structural equation modeling (SEM) using EQS 6 (Bentler 1985; Bentler 1995). In the measurement model, once each latent variable was operationalized, the construct of each factor was examined to confirm its dimensionality using Confirmatory Factor Analysis (CFA). In the last phase, the structural model, which specifies the relationships between the variables, was tested using maximum likelihood estimation. Based on Hu and Bentler's (1999) recommendation, a combination of two indices of fit was considered to determine whether the model fit the data: Comparative Fit Index (CFI) and Root Mean Square Error of Approximation (RMSEA). The cutoff criteria/values for accepting the model were CFI $\geq .95$ and RMSEA <.08 (Hu and Bentler 1999). These indices have been shown to be free of sampling bias (Hu and Bentler 1999). As part of the model testing, the parameter estimates were also examined to see if there were irregular values such as unexpected signs or extreme values. The minimum sample size required was determined based on Bentler's and Chou's (1987) rule. They suggested two criteria: 1) a minimum of 5 cases per parameter estimate in the model, and 2) a minimum of 15 cases per measured variable. Given that in each model we had 27 estimated parameters, the minimum required sample size based on the first criteria was 135 $(27 \times 5)$. As each model included 11 measured variables, the minimum required sample size based on the second criteria was $165(11 \times 15)$. Thus, our sample size $(n=288)$ had more than the minimum required to test using SEM.

\section{Results}

\section{Sample Characteristics}

The demographic analysis of the 288 participants indicated that $39 \%$ were men, with the sample's mean age of 38.6 ( $\mathrm{SD}=9.1)$. Eighty percent of the participants were married/living with a partner and $70 \%$ had children. Participants had a mean of 15.7 $(\mathrm{SD}=2.5)$ years of education. Forty-seven percent of the participants' income was above the mean Israeli income and their household density (number of people per room) ranged from 0.2 to 2 (mean $=0.83, \mathrm{SD}=0.29$ ).

The majority of the sample (68\%) was located in urban areas, $20 \%$ lived in suburban areas and the rest (12\%) lived in rural areas. Participants' overall mean working hours per week was 43.9 ( $\mathrm{SD}=12.1)$; most were professionals (58\%) (e.g., engineers), some were associated professionals (17\%) (e.g., computer technicians); $11 \%$ were clerks; and the rest (14\%) had jobs that were classified within the basic range (e.g., transit operators).

The means, standard deviations and the inter-correlation matrix between all the variables included in the model are presented in Table 1 (with the exception of occupational characteristics as these variables were tested separately in a different model each time). Level of occupational imbalance was relatively low (mean=1.98, 


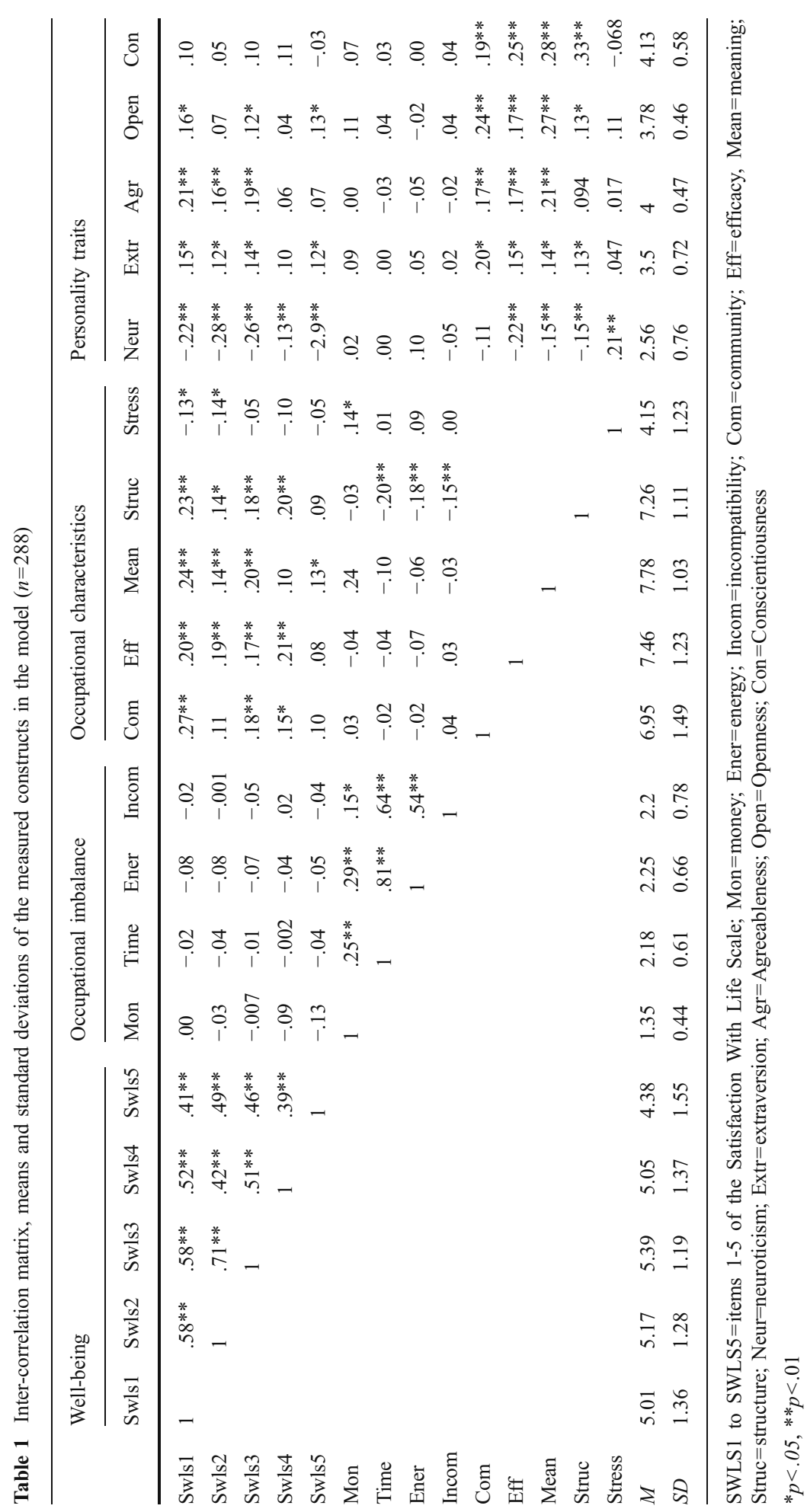


$\mathrm{SD}=.49$ ) with little variability (interquartile range 1.97-2.29). Level of life satisfaction (mean=24.9, $\mathrm{SD}=5.25)$, falling in between 21 and 25, represented the upper limit of the slightly satisfied level (Pavot and Diener 1993).

Demographic variables such as gender and SES had no association with the model outcome, that is well-being, whereas age had a small association $(r=0.14$, $p=0.015$ ) with well-being.

As shown in the inter-correlation matrix (Table 1), the correlations between the indicators of well-being were moderate to strong. The correlations between the occupational imbalance indicators had similar strength, except for the 'money' indicator which had the lowest correlations with the rest of the indicators.

\section{The Measurement Model}

The factorial structure of the two latent variables in the model (Occupational imbalance and well-being) was tested using CFA. The single factor-structure of well-being was confirmed $(\mathrm{CFI}=0.99$; RMSEA=0.076). Similarly, indices of fit confirmed a one factor solution for the concept of occupational imbalance $(\mathrm{CFI}=0.996$; $\mathrm{RMSEA}=0.061)$.

\section{The Structural Model}

Indices of fit indicated that all 25 models fit the data wherein CFI values were above 0.97 and RMSEA were less than 0.07 (see Table 2 and 3 for specific values for each model). However, not all the paths (effects) were significant. Several patterns were identified across models:

The Role of Occupational Imbalance in the Models Occupational imbalance did not play a significant role in the presence of personality traits and occupational characteristics. It is noteworthy that occupational imbalance did not function as a mediator, contrary to what was expected in the proposed theoretical model.

The Role of Occupational Characteristics in the Models Our model proposes both a direct effect of personality on well-being and an indirect effect through occupational characteristics. Inspired by an occupational science perspective, we were more interested in cases where personality affected well-being only indirectly (through occupational characteristics). The sole indirect path highlights the role of occupational characteristics as an exclusive mediator where without the occupational characteristics the effect of personality on well-being would not exist. Thus, we examined the frequency of indirect and direct paths, which were significant, between personality and well-being (see Table 4).

The occupational characteristics of 'Community', 'Efficacy' and 'Meaning' consistently served as significant mediators for all five personality traits. The highest frequency of significant indirect paths was in the presence of 'community' and 'efficacy'. In other words, 'community' and 'efficacy' served as exclusive mediators three times, where without their presence the effect of personality on well-being would have not been evident. Meaning was the next most frequent mediator and served as an exclusive mediator twice. Finally, 'structure' served as a mediator in four of the five models, except for agreeableness, and was an exclusive mediator 
Table 2 The structural relations among personality traits of Neuroticism, Extraversion and Agreeableness across the five occupational characteristics

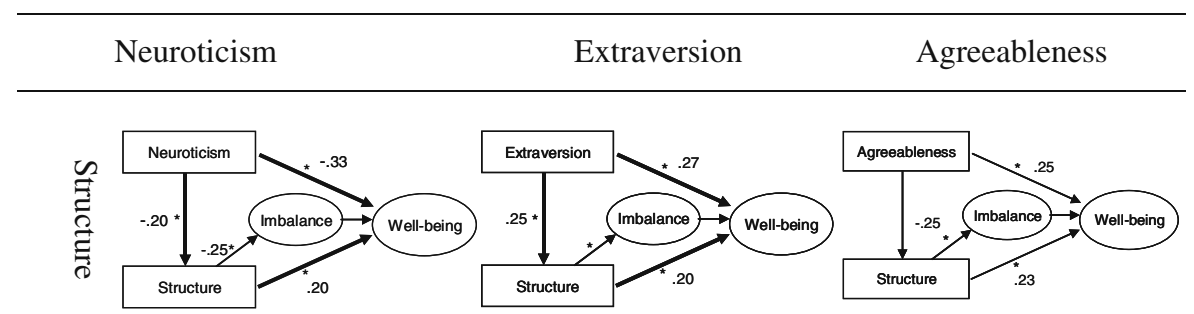

$\mathrm{CFI}=.98, \mathrm{RMSEA}=.054, \mathrm{R}^{2}=.17$

$\mathrm{CFI}=.99$, RMSEA $=.045, \mathrm{R}^{2}=.14$

$\mathrm{CFI}=.98, \mathrm{RMSEA}=.039, \mathrm{R}^{2}=.13$
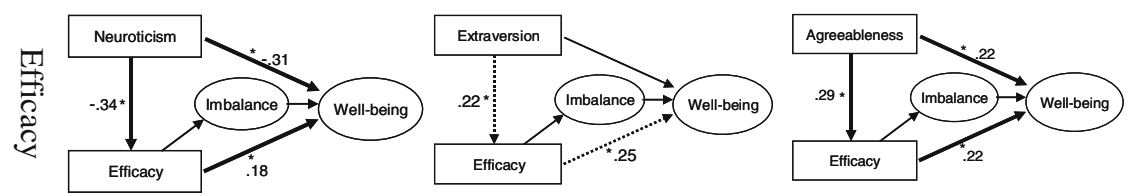

$\mathrm{CFI}=.98, \mathrm{RMSEA}=.051, \mathrm{R}^{2}=.17$

$\mathrm{CFI}=.99, \mathrm{RMSEA}=.042, \mathrm{R}^{2}=.10$

$\mathrm{CFI}=.98, \mathrm{RMSEA}=.042, \mathrm{R}^{2}=.13$
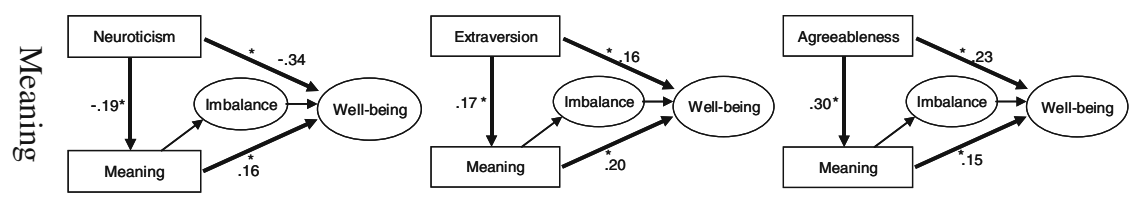

$\mathrm{CFI}=.99, \mathrm{RMSEA}=.055, \mathrm{R}^{2}=.16$

$\mathrm{CFI}=.99, \mathrm{RMSEA}=.047, \mathrm{R}^{2}=.08$

$\mathrm{CFI}=.99, \mathrm{RMSEA}=.047, \mathrm{R}^{2}=.10$
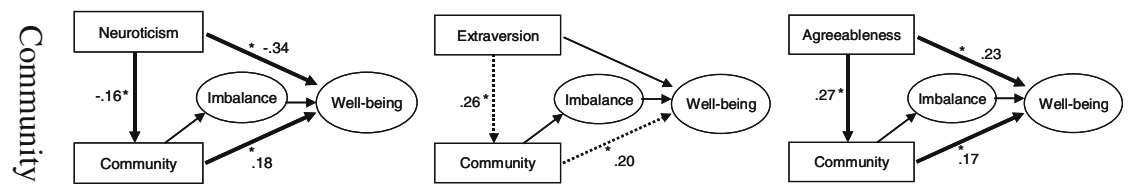

$\mathrm{CFI}=.98, \mathrm{RMSEA}=.058, \mathrm{R}^{2}=.17$

$\mathrm{CFI}=.98, \mathrm{RMSEA}=.05, \mathrm{R}^{2}=.08$

$\mathrm{CFI}=.98, \mathrm{RMSEA}=.05, \mathrm{R}^{2}=.11$
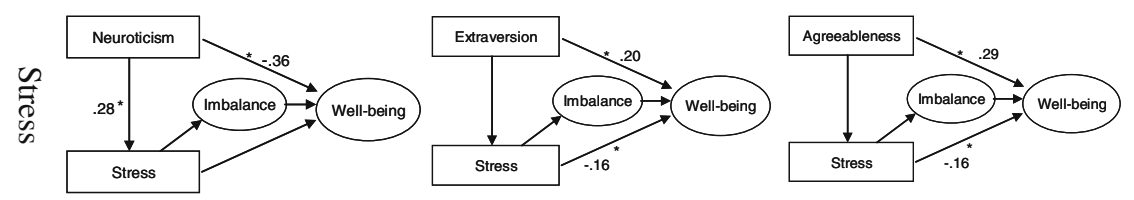

$\mathrm{CFI}=.98, \mathrm{RMSEA}=.056, \mathrm{R}^{2}=.14$

$\mathrm{CFI}=.98, \mathrm{RMSEA}=.049, \mathrm{R}^{2}=.07$

$\mathrm{CFI}=.98, \mathrm{RMSEA}=.05, \mathrm{R}^{2}=.11$

Note. ${ }^{*}=$ significant path; Bold paths denote the mediating role of occupational characteristics; Lined paths denote the role of occupational characteristics as exclusive mediators; CFI= Comparative Fit Index; RMSEA= Root Mean Square Error of Approximation; $\mathrm{R}^{2}=$ the well-being variance explained by the model.

twice. Interestingly, looking at 'stress' across all the personality trait models revealed that it did not function as a significant mediator in any of the models.

In summary, in 19 out of the 25 models (76\%), occupational characteristics functioned as a mediator (see Table 4). The occupational characteristics that 
Table 3 The structural relations among personality traits of Openness and Conscientiousness across the five occupational characteristics

Openness

\section{Conscientiousness}

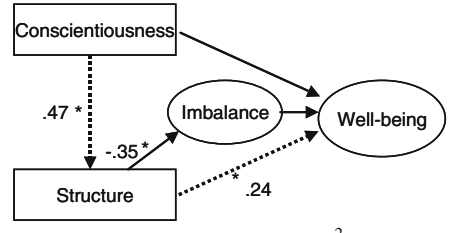

$\mathrm{CFI}=.99, \mathrm{RMSEA}=.044, \mathrm{R}^{2}=.08$

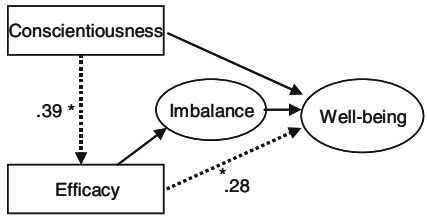

$\mathrm{CFI}=.99, \mathrm{RMSEA}=.041, \mathrm{R}^{2}=.08$

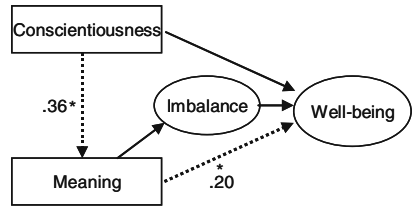

$\mathrm{CFI}=.99, \mathrm{RMSEA}=.049, \mathrm{R}^{2}=.05$

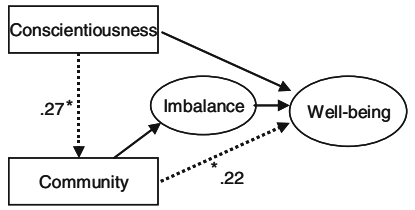

$\mathrm{CFI}=.98, \mathrm{RMSEA}=.05, \mathrm{R}^{2}=.06$

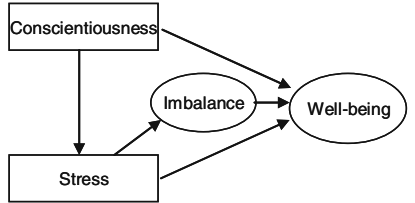

$\mathrm{CFI}=.98, \mathrm{RMSEA}=.05, \mathrm{R}^{2}=.04$

Note. ${ }^{*}=$ significant path; Bold paths denote the mediating role of occupational characteristics; Lined paths denote the role of occupational characteristics as exclusive mediators; CFI= Comparative Fit Index; RMSEA= Root Mean Square Error of Approximation; $\mathrm{R}^{2}=$ the well-being variance explained by the model.

functioned as mediator most frequently were community, efficacy and meaning followed by structure, whereas 'stress' did not serve as a mediator at all. Most notably, in 10 of the 19 mediated models (52\%), occupational characteristics served as exclusive mediators between personality and well-being such that 
Table 4 Frequencies of the mediating role of occupational characteristics across the 25 models

$O C=$ occupational characteristic; Exclusive mediator $=$ the effect of personality on wellbeing exists only through $\mathrm{OC}$
Number of times OC Number of times OC total served as a mediator served as an exclusive mediator

\begin{tabular}{llll}
\hline Community & 5 & 3 & 8 \\
Meaning & 5 & 2 & 7 \\
Efficacy & 5 & 3 & 8 \\
Structure & 4 & 2 & 6 \\
Stress & 0 & 0 & 0 \\
total & $19(76 \%)$ & $10(52 \%)$ & \\
\hline
\end{tabular}

without their presence the effect of personality on well-being would not have taken place.

The Role of Personality Traits in the Models All personality traits across all the 25 models had an effect on well-being either directly or indirectly. Neuroticism and agreeableness had a direct effect on well-being across all the models. In fact, when neuroticism was present in the models, across all the five occupational characteristics, the models could account for the largest portion of the well-being variance $(14 \%-17 \%)$. As we were interested in the exclusive indirect effect between personality and wellbeing (through occupational characteristics), it appeared that neuroticism, extraversion, openness and conscientiousness influenced well-being indirectly four times. On the other hand, agreeableness had an indirect effect on well-being 3 times (see Table 5).

The Directions of the Effects in the Models When occupational characteristics served as a mediator between personality and well-being (overall 19 models) the following patterns were identified across all the models: When neuroticism was present in the models it had a negative effect on the four occupational characteristics. In other words, higher level of neuroticism was associated with occupations characterized by lower levels of efficacy $(-0.34)$, meaning $(-0.19)$, structure $(-0.2)$ and community $(-0.16)$, which were associated with lower levels of well-being. On the other hand, higher levels of personality traits such as extraversion, agreeableness, openness and consciousness had a positive indirect effect on well-being through the four occupational characteristics. That means that higher levels of these personality traits were associated with occupations characterized by higher levels of community (i.e., supported by others), meaning (i.e., congruent with one's values), structure (i.e., well organized and under control) and efficacy (i.e., in a state of progress through

Table 5 Frequency of significant paths between personality traits and well-being across the 25 models

\begin{tabular}{lcc}
\hline & $\begin{array}{c}\text { Number of } \\
\text { direct paths }\end{array}$ & $\begin{array}{l}\text { Numbers of } \\
\text { indirect paths }\end{array}$ \\
\hline Neuroticism & 5 & 4 \\
Extraversion & 3 & 4 \\
Conscientiousness & 0 & 4 \\
Openness & 0 & 4 \\
Agreeableness & 5 & 3 \\
\hline
\end{tabular}


accomplishment), and higher levels of well-being. See Table 2 and 3 for coefficients values.

\section{Discussion}

This study had proposed and tested a theoretical model for explaining well-being with a convenience sample of working adults living in Israel. More specifically, we aimed to confirm the proposed structural relations between personality, occupational characteristics, occupational imbalance and well-being. Overall, the 25 models that were proposed held up to empirical testing; however our hypotheses were partially confirmed. Occupational characteristics served as significant mediators, yet occupational imbalance did not. The following discussion will present several explanations for our findings while proposing suggestions for future research.

\section{The Role of Occupational Characteristics in the Models}

The majority of the models indicated that all occupational characteristics, with the exception of stress, served as a mediator between personality traits and well-being. For example, well-being was influenced by the level of meaning in occupations, which in turn was dependent upon the level of neuroticism. This finding has an important theoretical and empirical contribution. First it provides empirical support to Little's (1999) socio-ecological model that links personality traits with PAC units (e.g., occupations) and positions them as mediators between one's disposition and well-being. In fact, in $52 \%$ of the models, personality could have an effect on well-being only through its effect on occupations. This lends more substantial support for the importance of occupation to well-being, in spite of the powerful presence of personality.

In addition, as one's occupations can be altered, while personality is a relatively stable construct (Diener et al. 1999), the findings of this study might have clinical implications and guidance for policy makers. Therefore, this study further advocates for the salient role of health professionals who focus on occupation to promote their clients' well-being in situations of disability and life transitions. Moreover, these findings might serve as a building block for future studies aiming to evaluate the effectiveness of occupation-based intervention. These studies might address in their intervention plan the level of community, efficacy, meaning and structure in one's array of occupations as they were found to be significant mediators in this study.

The occupational characteristic of community served as a mediator across all personality traits but it also functioned, in most cases, as an exclusive factor where personality could affect well-being solely through community. The community factor refers to the way the individual perceives how others perceive their occupations and support them. One might say that the social aspect of the occupation is captured by this characteristic. This means that regardless of one's disposition, it is important for individuals' well-being to be perceived by others positively, to gain others' acceptance and value through occupations. Interestingly, 
this finding falls within Renwick et al. (1996) notion of being, belonging and becoming as indicators for quality of life among people with disabilities. It is important for people to be part of their community, to have a sense of belonging and to become a contributing member to society through participation in different life situations. Participating in life situations has been recognized by the World Health Organization (2001) as one of the domains underpinning health, and the present findings support the importance of the lived experience of persons in a societal context as stated by the International Classification of Function Disability and Health (WHO 2001). As our sample included only people free from mental or physical disabilities, it would be worthwhile to examine in future studies whether the concept of community, reflected in occupations, would be similar within people with disability or in various life transitions (e.g., retirement, immigration) where occupations are often disrupted.

Although the extent to which ones' occupations is supported by others (community factor) was measured using only two items (other's view and visibility), it was still a salient factor in predicting well-being in our study. As this community factor represents a relatively narrow contextual aspect of occupation, future studies might expand and explore additional components of the community as well as additional facets of the social environment reflected in occupations. Examples of additional components might be: 1) the level of actual assistance received from others (e.g., friends, family, and social policy) to carry out an occupation 2) the extent to which one feels their occupations are restricted to or liberated from their environmental expectations, and 3) the extent to which they are satisfied with the relationship that exists between their occupations and their environmental demands. Such inclusive information about the community aspect of occupations might better explain individuals' level of occupational balance as well as their well-being.

The occupational characteristics of efficacy, meaning and structure also served as significant mediators in the models where their effect on well-being was positive, as expected. These findings are in line with previous studies showing that meaningful, well-organized, supported and efficient occupations were associated with higher levels of well-being (Christiansen et al. 1999; McGregor and Little 1998; Yetim 1993). It is somewhat surprising that occupations characterized by stress did not serve a significant role, especially in the face of considerable evidence that stress, reflected in occupations, explains well-being (Christiansen et al. 1999; Lecci et al. 1994; Palys and Little 1983; Wallenius 2000; Wallenius 1999). One explanation might be embedded in our sample. Not only did our participants report lower levels of stressful occupations, but the stress variability was relatively small (and unexpectedly was only correlated to one personality trait: neuroticism). It is plausible that a wider range of levels of stress might have yielded different results. Perhaps engaging in occupations that are congruent with one's values (meaning), supported by others (community), well-organized (structure) and which are in a state of progress toward successful accomplishment (efficacy) acts as an antidote for feelings of stress in these occupations. Another explanation might be embedded in stress related theories that suggest that the relationship between stress and well-being is not linear. For example, the Demand-Control Model of work (Karasel and Theorell 1990) suggests that while high level of stress in work is related to lower levels of well-being, this negative effect might be moderated by the level of control 
one has on their occupation. Similarly, Zuzanek (1998) claimed that lower levels of mental health are associated with both high and low level of stress. Moreover, the way stress was measured by the PPA might be questioned as one of the items addressed level of challenge in occupations. Challenge might have an ambiguous meaning as in certain conditions it can have a reverse effect on well-being. Based on the flow theory (Csikszentmihalyi 1997) situations in which the level of challenge matches one's skills can evoke positive effect, whereas in situations when the demands of the occupation are too challenging for the doer or not challenging enough it may provoke a negative effect. Certainly the role of stress, reflected in occupations, and its relation to well-being requires further study which focuses on other characteristics of the occupation that might play as moderators.

\section{The Role of Occupational Imbalance}

Unexpectedly, occupational imbalance did not prove to be a significant mediator between occupational characteristics and well-being across all the models. Possible explanations for this are embedded in the way imbalance was measured and in our sample characteristics. Our results indicate that occupational imbalance did not affect well-being directly. Few previous studies showed that interference among occupations, measured by the IRQ, was correlated with well-being; however the method in which well-being was measured in those studies was different. Life satisfaction was measured using a combined score of two measurements relevant to the German context (Riediger and Freund 2004; Riediger 2007). In fact, this combination score has been validated only once. In this study, on the other hand, life satisfaction was measured by the SWLS, a well-accepted measure that represents the cognitive aspect of well-being. This might relate to the difference between the results of this study and those of Riediger and Freund (2004).

Our sample was characterized by relatively low levels of imbalance (mean $=1.98$, $\mathrm{SD}=0.49$ ), with relatively little variability of its items, in particular the item related to financial constraints (i.e., money). In addition, our sample had a relatively high level of socio-economic status (SES) based on income, education and household density. It is plausible that our participants were able to afford to hire help with occupations, minimizing the conflict across occupations particularly those that involve money constraints. Most importantly their SES might enable them to choose which occupations they want to carry out in a way that would have decreased the inevitability of giving up valued pursuits. Indeed having a wider range of variability in the level of imbalance might better explain well-being. Thus, future studies should explore the role of occupational imbalance in different samples and use different measures in order to fully investigate this potential relationship before concluding that it does not exist.

Another explanation for this finding lies in the way occupations were elicited, chosen and rated. Participants were asked, in the first module of the PPA, to list 10 occupations they were engaged in. Then, using the IRQ matrix, they were asked to choose four which they considered to be core occupations and evaluate the impact of those occupations on each other. However, a few salient questions were left unanswered: Do participants choose to engage in occupations that are a priori less 
likely to be in conflict with one another? What are the occupations that they were willing to give up? Did they give up valuable occupations? What is the process underlying this decision-making? The PPA and the IRQ do not provide us with this valuable information. Westhorp (2003) claimed that one of the greater skills for achieving balance is embedded in the process of choosing occupations that can be managed; these which are compatible with one's resources and capabilities. Sometimes an occupation needs to be given up in order to keep a manageable array of occupations (or a balanced state). This might affect one's well-being particularly if that specific occupation was valuable to them. In order to better understand the process of choosing occupations, in depth interviews should take place while the participants complete the PPA and IRQ. In future studies participants might be asked to identify occupations that were given up and to reflect on the congruency between their occupations and their values. Such information might serve as a preliminary step in capturing the concept of occupational imbalance more accurately.

Another question that might be raised is related to the process underlying the completion of the IRQ. In the IRQ, participants rated the impact of their occupations on each other in terms of resource constraints (time, energy, money) and incompatibility among occupations. Do participants consider additional criteria to base their judgment while comparing the impact of each occupation on another? For example, is the affective experience of the occupation taken into consideration while rating? Could it be that engaging in one occupation might charge one's energy budget rather than empty it? Say a person has two occupations writing a paper and chairing the annual meeting on women's rights. Both occupations compete for one's energy, but it could also be that they are so meaningful to the doer and intrinsically rewarding that they play as a source of energy. That experience might replenish one's batteries in a way that would decrease the level of interference between these two occupations or level of occupational imbalance. This is compatible with Marks' (2009) approach to human energy where individuals become charged with attentiveness and energy due to the interest they find in a certain activity they are engaged in. Indeed, carrying out an occupation involves an expense of energy, but at the same time it might also provide energy (Håkansson et al. 2006). However, the IRQ refers to energy as a resource constraint. One might say that the concept of energy is perceived differently across the participants and is influenced by other aspects of the occupation. In fact, there are many different combinations of impacts among occupations and we do not know exactly what our participants were thinking while evaluating this impact. A mixed-method approach, that combines qualitative methods (in-depth interview) and quantitative methods (using IRQ) might be helpful in clarifying these issues.

The theoretical aspect which the concept occupational imbalance was derived from in this study might be reexamined. Recent theoretical aspects of occupational balance, emerging in the current literature, introduce a different perception of occupational balance. In an attempt to define the concept, the current focus is on the quality of one's occupations. For example, balance is perceived as a state where one's occupations meet one's psychological needs (Christiansen and Matuska 2006); are congruent with the individuals' values (Pentland and McColl 2008) and provide affective experience that promotes well-being (Jonsson and Persson 2006). These innovative approaches for life balance draw researchers' attention to the quality of one's occupations, their nature, and their characteristics. One might say that the 
quality of occupations, which proposed to reflect a level of balance, is somewhat being captured by the "occupational characteristics" factor in our model. For example, the occupational characteristic of meaning embeds occupations that are congruent with one's values and identity, which are considered as important and enjoyable; these occupations which individuals are profoundly engaged in. Perhaps an extended format of the PPA might capture these qualities of occupations that are important to balance. However, further studies are needed to clarify the specific characteristics of occupations that represent a balanced life and how the new definitions to balance can be operationalized. It is plausible to say that our findings provide initial support for the new conceptual definitions of balance that focus on the quality of occupation, as we found that occupational characteristics played a significant role in explaining well-being. Indeed, further studies are needed to clarify the complex concept of occupational balance using triangulated methods.

\section{The Role of Personality}

Personality traits had a consistent effect, whether directly or indirectly, on well-being across all models as expected. Coming from an occupational perspective, we were interested in the effect of personality on well-being through occupational characteristics. Neuroticism, extraversion, openness and conscientiousness demonstrated this indirect effect most frequently (four out of five times). In the presence of neuroticism across all occupational characteristics the models could explain the greatest amount of the well-being variance. However, in the presence of conscientiousness and openness the smallest amount of variance in well-being was explained. In fact, conscientiousness and openness affected well-being only indirectly through their effect on occupational characteristics. This might indicate their weakness in influencing well-being independently. These findings corroborate well-being literature where neuroticism and extraversion are considered as the most influential traits (Diener et al. 1999; DeNeve and Cooper 1998).

In some cases, personality could affect well-being only through its effect on occupations. For example, extraversion did not influence well-being on its own and required the presence of community-related occupations. It is plausible that the behavioral tendency of extraverted people, who seek social stimulation, is highly expressed in their occupations which are more community-oriented, supported and visualized by others. An alternative explanation is that all the effect of extraversion is explained by the effect of extraversion on community-related occupations.

Although traits are considered powerful factors in their ability to explain wellbeing, our findings imply that studying individuals' behaviors cannot rely only on one level of personality research, such as traits. Little (1996) has termed this level of one's traits as the having aspect of personality. This study supports his argument that additional levels of investigation should be included such as the doing aspect of personality which is reflected in one's occupations, personal projects or goals (Little et al. 1992). Future studies might consider additional levels such as the narrative accounts of what people do, termed by Little (1996) as the being aspect of personality. Such an inclusive perspective of personality might explain well-being further more. 


\section{Limitations}

As a cross-sectional study no absolute cause and effect claims can be made. However, as the models fit the data well, the SEM allows us to conclude the dependency between the variables. Future studies (i.e., longitudinal and pre/post semi-experimental design) are needed to confirm this study's proposal of the structural relation between the variables. In addition, testing this study's model during fragile life situations where one's occupations are being disrupted (e.g., becoming a care-giver, retirement, acquired disability unemployment) is critical. At these points of time the level of imbalance might increase and jeopardize one's internal set level of well-being (Cummins et al., in press). It might be that in these situations the effect of one's occupation and occupational imbalance on well-being will be more profound.

It is worthwhile noting that this study was carried out with a convenience sample, which was quite homogenous and therefore may not be representative of the population. This might limit its generalizability. However, based on normative data, the sample's life satisfaction score had a similar distribution to other non clinical samples (Pavot and Diener 1993).

Specific cultural aspects may have affected our findings, which therefore need to be interpreted with care. For example, the concept of stress, reflected in one's daily occupations, might play a significant factor in predicting well-being among people from different political contexts (Wallenius 2007). Moreover, Israelis might perceive imbalance among occupations differently as their overall daily life dynamics fluctuate. They tend to engage in occupations spontaneously, in a less formal and structured way, which does not necessarily follow a restricted plan or a firm rhythm. In fact, disruption in daily routine is a familiar state in an ongoing threat of terrorism. As a result Israelis have developed resilient coping strategies to maintain their habitual lifestyle (Pat-Horenczyk 2006).

\section{Conclusions}

Our study provides substantial support for the notion that occupation affects well-being. The fact that occupational characteristics served as a mediator between personality and well-being is important from both a theoretical and clinical perspective. Personality is a fairly stable construct that is less amenable to change whereas occupations can be altered and redesigned. Thus, occupations serve as a fertile ground for intervention that might lead to a change in one's well-being. Future occupational-based intervention studies are needed among different populations across the life span. Findings from this study may serve as empirical evidence when communicating with policy makers; in fostering for supportive environments for participation in occupations that promote individuals' well-being and in advocating for building healthy public policy. In addition, results may guide the development and testing of the effectiveness of occupational programs/opportunities in the community in accordance to cultural groups and age. Finally another line of inquiry might be to examine how occupational consultant services or programs in the workplace can enhance employees' well-being.

The notion of the social environment reflected in one's occupation (community factor) was also an interesting finding. Our findings suggest that the extent to which 
individuals believe that their occupations are perceived by others as important and valuable is salient to their well-being. This might draw therapists' attention to the social context as a facilitator or a barrier, especially as clients are struggling with the issue of stigma. However, further studies with people with disability are needed to verify this assumption.

Certainly, the concept of occupational imbalance needs to be reexamined. Three directions of inquiry might take place: 1 ) reexamining the process that underlies the completion of the PPA and the IRQ using qualitative methods while focusing on the process of choosing occupations, identifying the occupations that were given up and reflect on their values 2) embracing innovative theories for defining life balance while focusing on the quality of one's occupations (value, meaning) rather than on the way occupations are being constructed and managed (e.g., Pentland and McColl 2008), and 3) developing new tools that are congruent with the evolving definitions of the concept.

\section{References}

Anaby, D. Jarus, T., \& Zumbo, B. (2010). Psychometric evaluation of the Hebrew language version of the Satisfaction with Life Scale. Social Indicators Research, 96, 267-274.

AOTA. (2002). Occupational therapy practice framework: domain and process. American Journal of Occupational Therapy, 56, 609-639.

Arrindell, W. A., Meeuwesen, L., \& Huyse, F. J. (1991). The satisfaction with life scale (SWLS)psychometric properties in a nonpsychiatric medical outpatients sample. Personality and Individual Differences, 12, 117-123.

Backman, C. (2001). Occupational balance: Measuring time use and satisfaction across occupational performance areas. In M. Law, C. Baum, \& W. Dunn (Eds.), Measuring occupational performance: Supporting best practice in occupational therapy (pp. 203-213). Thorofare: Slack.

Backman, C. L. (2004). Occupational balance: exploring the relationships among daily occupations and their influence on well-being. Canadian Journal of Occupational Therapy, 71, 202-209.

Bentler, P. M. (1985). Theory and implication of EQS: A structural equations program. Los Angeles: BMDP Statistical Software.

Bentler, P. M. (1995). EQS structural equations programs manual. Enrico: Multivariate Software, Inc.

Bentler, P. M., \& Chou, C. P. (1987). Practical issues in structural modeling. Sociological Methods \& Research, 16, 78-117.

Bollen, K. A., \& Long, J. S. (1993). Testing structural equation models. Newburyk Park: Sage.

Byrne, B. M. (2006). Structural equation modeling with EQS: Basic concepts, applications, and programming (2nd ed.). Mahwah: Erlbaum.

Canadian Association of Occupational Therapists. (1997). Enabling occupation: An occupational therapy perspective. Ottawa: Canadian Association of Occupational Therapists.

Christiansen, C. H. (1996). Three perspectives on balance in occupation. In R. Zemke \& F. Clark (Eds.), Occupational science: The evolving discipline (pp. 431-451). Philadelphia: F.A. Davis.

Christiansen, C. (2000). Identity, personal projects and happiness: self construction in everyday action. Journal of Occupational Science, 7, 98-107.

Christiansen, H. C., \& Baum, M. C. (2005). Humans as occupational beings (understanding human occupation). Occupational therapy: Performance, participation, and well-being (3rd ed., pp. 2-22). Thorofare, NJ: Slack.

Christiansen, C. H., \& Matuska, K. M. (2006). Lifestyle balance: a review of concepts and research. Journal of Occupational Science, 13, 49-61.

Christiansen, C. H., Backman, C., Little, B. R., \& Nguyen, A. (1999). Occupations and well-being: a study of personal projects. American Journal of Occupational Therapy, 53, 91-100.

Clark, F., Azen, S. P., Zemke, R., Jackson, J., Carlson, M., Mandel, D., et al. (1997). Occupational therapy for independent-living older adults: a randomized controlled trial. JAMA: Journal of the American Medical Association, 278, 1321-1326. 
Csikszentmihalyi, M. (1997). Finding flow: The psychology of engagement with everyday life (1st ed.). New York: BasicBooks.

Csikszentmihalyi, M., \& Hunter, J. (2003). Happiness in everyday life: the uses of experience sampling. Journal of Happiness Studies, 4, 185-199.

Cummins, R. A., Lau, A. D. L., \& Davern, M. (in press). Homeostatic mechanisms and the quality of life. In K. C. Land (Ed.), Handbook of social indicators and quality of life studies. Theoretical and methodological foundation. New York: Springer.

DeNeve, K. M., \& Cooper, H. (1998). The happy personality: a meta-analysis of 137 personality traits and subjective well-being. Psychological Bulletin, 124, 197-229.

Diener, E., Emmons, R. A., Larsen, R. J., \& Griffin, S. (1985). The satisfaction with life scale. Journal of Personality Assessment, 49, 71-75.

Diener, E., Suh, E. M., Lucas, R. E., \& Smith, H. L. (1999). Subjective well-being: three decades of progress. Psychological Bulletin, 125, 276-302.

Diener, E. (1984). Subjective well-being. Psychological Bulletin, 95, 542-575.

Furnham, A. (1981). Personality and activity preference. British Journal of Social Psychology, 20, 57-68.

Håkansson, C., Dahlin-lvanoff, S., \& Sonn, U. (2006). Achieving balance in everyday life. Journal of Occupational Science, 13, 74-82.

Hu, L., \& Bentler, P. M. (1999). Cutoff criteria for fit indexes in covariance structure analysis: conventional criteria versus new alternatives. Structural Equation Modeling, 6, 1-55.

Jöreskog, K., \& Sörbom, D. (1993). LISREL 8 user's reference guide. Chicago: Scientific Software International.

John, O. P., \& Srivastava, S. (1999). In L. A. Pervin \& O. P. John (Eds.), The big five trait taxonomy: History, measurement, and theoretical perspectives. New York: Guilford.

Jonsson, H., \& Persson, D. (2006). Towards an experiential model of occupational balance: an alternative perspective on flow theory analysis. Journal of Occupational Science, 13, 62-73.

Karasek, R., \& Theorell, T. (1990). Healthy work: Stress, productivity, and the reconstruction of working life. New York: Basic Books.

Law, M., Cooper, B. A., Strong, S., Stewart, D., Rigby, P., \& Letts, L. (1996). The person-environmentoccupational model: a transactive approach to occupational performance. Canadian Journal of Occupational Therapy, 63, 9-23.

Lawrence, R. J. (2006). Housing and health: beyond disciplinary confinement. Journal of Urban HealthBulletin of the New York Academy of Medicine, 83, 540-549.

Lecci, L., Karoly, P., Briggs, C., \& Kuhn, K. (1994). Specificity and generality of motivational components in depression - a personal projects analysis. Journal of Abnormal Psychology, 103, 404-408.

Little, B. R. (1983). Personal projects - a rationale and method for investigation. Environment and Behavior, 15, 273-309.

Little, B. R. (1984). Personal projects analysis - a methodology for the moral science of action. Bulletin of the British Psychological Society, 37, A115-A115.

Little, B. R. (1996). Free traits, personal projects and idio-tapes: three tiers for personality psychology. Psychological Inquiry, 7, 340-344.

Little, B. R. (1999). Personality and motivation: Personal action and the conative evolution. In L. A. Pervin \& O. P. John (Eds.), Handbook of personality: Theory and research (2nd ed., pp. 501-524). New York: Guilford.

Little, B. R. (2007). Prompt and circumstance: The generative contexts of personal project analysis. In B. R. Little, K. Salmela-Aro, \& S. D. Phillips (Eds.), Personal project pursuit: Goals, action, and human flourishing (pp. 3-49). Mahwah: Erlbaum.

Little, B. R., \& Chambers, N. C. (2004). Personal project pursuit: On human doings and well-beings. In W. M. Cox, E. Klinger, W. M. Cox, \& E. Klinger (Eds.), Handbook of motivational counseling: Concepts, approaches, and assessment (pp. 65-82). New York: Wiley.

Little, B. R., Lecci, L., \& Watkinson, B. (1992). Personality and personal projects: linking big five and PAC units of analysis. Journal of Personality, 60, 501-525.

Marks, S. R. (2009). Multiple roles and life balance: An intellectual journey. In K. M. Matuska, C. H. Christiansen, J. Davis, \& H. Polatajko (Eds.), Life balance: Multidisciplinary theories and research (pp. 43-58). Bethesda: AOTA.

McColl, M. A., Law, M., \& Stewart, D. (1993). Theoretical basis of occupational therapy: An annotated bibliography of applied theory in the professional literature. Thorofare: SLACK.

McDonald, A. R., \& Seifert, F. C. (1999). Full and limited information strategies for incorporating measurement error in regression models. Atlanta, GA. Paper presented at the Southern Management Association Meeting. 
McGregor, I., \& Little, B. R. (1998). Personal projects, happiness, and meaning: on doing well and being yourself. Journal of Personality and Social Psychology, 74, 494-512.

Meyer, A. (1977). Philosophy of occupation therapy. American Journal of Occupational Therapy, 31, 639-642.

Omodei, M. M., \& Wearing, A. J. (1990). Need satisfaction and involvement in personal projects - toward an integrative model of subjective well-being. Journal of Personality and Social Psychology, 59, 762-769.

Palys, T. S., \& Little, B. R. (1983). Perceived life satisfaction and the organization of personal project systems. Journal of Personality and Social Psychology, 44, 1221-1230.

Pat-Horenczyk, R. (2006). Terror in Jerusalem: Israelis coping with 'emergency routine' in daily life. In J. Kuriansky \& J. Kuriansky (Eds.), Terror in the holy land: Inside the anguish of the Israeli-Palestinian conflict (pp. 67-74). Westport: Praeger Publishers/Greenwood Publishing Group.

Pavot, W., \& Diener, E. (1993). Review of the satisfaction with life scale. Psychological Assessment, 5, $164-172$

Pentland, W., \& McColl, M. A. (2008). Occupational integrity: another perspective on "life balance". Canadian Journal of Occupational Therapy, 75, 135-138.

Reilly, M. (1966). Psychiatric occupational therapy program as a teaching model. American Journal of Occupational Therapy, 20, 61-67.

Renwick, R., Brown, I., \& Nagler, M. (1996). Quality of life in health promotion and rehabilitation: Conceptual approaches, issues, and applications. Thousand Oaks: SAGE.

Riediger, M. (2007). Interference and facilitation among personal goals: Age differences and associations with well-being and behavior. In B. R. Little, K. Salmela-Aro, \& S. D. Phillips (Eds.), Personal project pursuit: Goals, action, and human flourishing (pp. 119-143). Mahwah: Erlbaum.

Riediger, M., \& Freund, A. M. (2004). Interference and facilitation among personal goals: differential associations with subjective well-being and persistent goal pursuit. Personality and Social Psychology Bulletin, 30, 1511-1523.

Riediger, M., Freund, A. M., \& Baltes, P. B. (2005). Managing life through personal goals: intergoal facilitation and intensity of goal pursuit in younger and older adulthood. Journals of Gerontology Series B-Psychological Sciences and Social Sciences, 60, P84-P91.

Salmela-Aro, K., \& Little, B. R. (2007). Relational aspects of projects pursuits. In B. R. Little, K. Salmela-Aro, \& S. D. Phillips (Eds.), Personal project pursuit: Goals, action, and human flourishing (pp. 199-219). Mahwah: Erlbaum.

Vassar, M. (2008). A note on the score reliability for the satisfaction with life scale: an RG study. Social Indicators Research, 86, 47-57.

Wallenius, M. (1999). Personal projects in everyday places: perceived supportiveness of the environment and psychological well-being. Journal of Environmental Psychology, 19, 131-143.

Wallenius, M. (2000). Personal project level of abstraction and project conflict: relations to psychological well-being. European Journal of Personality, 14, 171-184.

Wallenius, M. A. (2007). Personal project content and stress: relations to subjective health and depressive mood. Social Indicators Research, 81, 35-50.

Watson, D., \& Clark, L. A. (1997). Extraversion and its positive emotional core. In R. Hogan, J. A. Johnson, \& S. R. Briggs (Eds.), Handbook of personality psychology (pp. 767-793). San Diego: Academic.

Wenzel, M. U. (2000). Goal striving among cardiac patients: a constructivist investigation of mood and rehabilitation enrollment. ProQuest Information \& Learning. Dissertation Abstracts International: Section B: The Sciences and Engineering, 61, 2229.

Westhorp, P. (2003). Exploring balance as a concept in occupational science. Journal of Occupational Science, 10, 99-106.

WHO. (2001). International classification of functioning, disability and health. Geneva: WHO.

Wilcock, A. A. (1998). An occupational perspective of health. Thorofare: SLACK, Inc.

Wilcock, A. A., Chelin, M., Hall, M., Hamley, N., Morrison, B., Scrivener, L., et al. (1997). The relationship between occupational balance and health: a pilot study. Occupational Therapy International, 4, 17-30.

Yerxa, E. J., Clark, F., Frank, G., Jackson, J., Parham, D., Pierce, D., et al. (1989). An introduction to occupational science, a foundation for occupational therapy in the 21 st century. Occupational Therapy in Health Care, 6, 1-17.

Yetim, U. (1993). Life satisfaction - a study based on the organization of personal projects. Social Indicators Research, 29, 277-289.

Zuzanek, J. (1998). Time use, time pressure, personal stress, mental health, and life satisfaction from a life cycle perspective. Journal of Occupational Science, 5, 26-39. 